\title{
Treating multiple antiaging pathways improves health markers in open label clinical study
}

\author{
Bryant Villeponteau ${ }^{1 *}$ (D) and Yvonne L. Still ${ }^{2}$
}

\begin{abstract}
Background: Research indicates that aging and health are affected by hundreds of biochemical pathways. Our hypothesis is that a multipath intervention strategy directed at multiple aging pathways may promote overall health. The objective of the study was to test the effects of a multipath antiaging dietary supplement on healthy adults using known markers of health.
\end{abstract}

Methods: The design of the dietary supplement intervention clinical study was an open-label field study. Fifteen men and women aged 42 to 79 years took a 10 component dietary supplement SC100+ twice daily for 15 weeks. Markers of overall health and life expectancy were measured at baseline and after 15 weeks of treatment. The markers included blood pressure, heart rate, HDL and Total Cholesterol, Stress levels, Lung capacity, and HbA1c. Paired two-sided Student t-tests were performed to evaluate the significance of the differences between baseline and post treatment.

Results: Mean laboratory measurements taken at baseline and after 15 weeks of SC100+ showed: 1) Systolic and diastolic blood pressure were both reduced (SBP $-10.1+/-6.37 \mathrm{mmHg}, p=0.013$ and DBP $-4.6+/-4.17 \mathrm{mmHg}, p=0.048$ );

2) Stress as measured by heart rate variability was reduced $(-25 \%, p=0.017) ; 3) \mathrm{HDL}$ cholesterol was increased

$(7.9+/-2.9 \mathrm{mg} / \mathrm{dL}, p=0.005)$; and 4$)$ Lung capacity was increased $(+16.6 \%, p=0.001)$. There were no significant changes in heart rate, total cholesterol, or HbA1c levels and no reported side effects.

Conclusions: Targeting multiple aging pathways has the potential to significantly reduce blood pressure and stress, while significantly increasing HDL Cholesterol levels and lung capacity. Targeting multiple critical aging pathways with a single dietary supplement is a novel alternative strategy to promote overall health.

Trial registration: The open label pilot study was registered retrospectively on Feb. 8, 2017 (NCT03052491).

Keywords: Aging, Antiaging, Blood pressure, HDL cholesterol, Stress, Lung capacity, Dietary supplement, Life expectancy

\section{Background}

Aging studies in many animal species have reported over a hundred genes linked to the aging process. These reported results provide evidence for the Evolution Theory of Aging [1, 2], which predicts that aging leads to poorly functioning organisms as optimal gene function and fitness decline with age after maturation to adulthood. The fact that many genes have altered expression with age suggests the hypothesis that a multipath strategy to nudge the expression of many critical genes back toward

\footnotetext{
* Correspondence: bvillepo@san.rr.com

${ }^{1}$ Centagen Inc., 637 S. Broadway St., Ste. B-206, Boulder, CO 80305, USA

Full list of author information is available at the end of the article
}

youthful fitness levels could help promote rejuvenation in older animals. Since aging plays a major role in agerelated diseases and overall health, a composite multipath approach targeting critical genes involved in aging could also promote overall health and extend life expectancy. This composite multipath supplement hypothesis was tested in Drosophila aging and was successful in significantly extending mean and maximum life span [3]. Overall health as measured by enhanced fertility also appeared to be improved by the composite multipath dietary supplement [3].

To test this composite multipath hypothesis in humans, we have completed a small open-label clinical trial that 
treated 15 subjects for 15 weeks with the multipath nutraceutical supplement $\mathrm{SC} 100+$ containing 10 active components. In designing the $\mathrm{SC} 100+$ composition, we have tried to target a critical number of the known pathways linked to health, fitness, and longevity: adult stem cell function, telomere loss, stress, diet or exercise induced inflammation, insulin-like growth factors, autophagy, vascular circulation, neural function, and oxidative stress.

In developing $\mathrm{SC} 100+$, we started with the major active compounds found in the composite multipath supplement that increased mean and maximum lifespan in Drosophila [3] and then added other nutraceutical compounds known to act on other critical age-related pathways. In adding more compounds, we identified the subset of the nutraceuticals that have a proven history of use in herbal medicine to treat pleotropic human health conditions. We also identified the subset of nutraceuticals that have little or no known side effects. Finally, we focused on stem cell function as a critical factor in rejuvenation [4-6] by screening candidate longevity nutraceuticals for their effectiveness in stimulating and/or maintaining adult stem cell growth in human tissue culture screens. As we detail below, the final 10 herbal extracts in $\mathrm{SC100+}$ provide a diverse set of bioactive compounds, which appear to act on many of the critical health and longevity pathways.

The first nutraceutical component in SC100+ comes from extracts of the Chinese medicinal herb Astragalus membranaceus, which has been used for thousands of years in Traditional Chinese Medicine (TCM) to promote cardiovascular and immune health. Astragalus extracts have many positive effects on stem cell function [7-10] and cardiovascular [11-14] and immune function [15-18]. Astragalus Polysaccharides activate autophagy [19], which is a potent cellular regenerative process.

The second nutraceutical component in $\mathrm{SC} 100+$ is Rhodiola rosea root extract, which helps to reduce several types of stress in humans [20, 21]. Rhodiola rosea extracts also have extended lifespan in several animal models [22-25], which suggest a positive effect on life expectancy.

The third major herbal extract in $\mathrm{SC} 100+$ is Vaccinium uliginosum berry extract, which has been standardized for a high content of resveratrol analogs. Resveratrol analogs help produce healthy levels of PPAR $\alpha$ and cholesterol [26], AMPK [27, 28], SIRT1 [27, 28] and diet or exercise induced inflammation [29-31]. As these targets are linked to positive effects on health, overall health could be enhanced.

The fourth major herbal extract in SC100+ is Tulsi (Ocimum Santum) leaf extract, which is an adaptogenic herb used in Indian Ayurvedic medicine to promote wound healing [32-35]. Tulsi extracts also reduce stress and promote health [36-38].
The fifth herbal extract in SC100+ is Pine Bark Extract (PBE), which is standardized to over 94\% proanthocyanidins. PBE improves endothelial function via activation of endothelial nitric oxide synthesis $[39,40]$ and promotes the vascular system [39] while reducing DNA damage [41] and oxidative stress [42].

The sixth herbal extract in SC100+ is L-Theanine, which is a unique neuroprotective amino acid found in green tea that crosses the blood-brain barrier. L-Theanine has a structure similar to glutamate, which is a neurotransmitter related to memory, and binds to the gamma-Aminobutyric acid (GABA) receptors in neurons. L-Theanine is reported to reduce mental stress and to promote health, while improving cognition and protecting neurons [43-47]. Moreover, L-Theanine is reported to facilitate neurogenesis in the hippocampus of rats, leading to enhanced memory [48]. As to its antiaging effects, L-Theanine extends the lifespan of C. elegans [49] and can suppress the shortened life span and learning impairment of senescence accelerated mice under stress [50].

The seventh component in $\mathrm{SC} 100+$ is genistein, which is an isoflavone phytoestrogen that activates telomerase, metabolic PPARs, autophagy (cell waste disposal), and AMPK [51-54]. Genistein also extends C. elegans lifespan and healthspan [55], so it promotes life expectancy in some animals.

The eighth component in $\mathrm{SC100+}$ is methylfolate (5MTHF), which is the methylated active form of the $B$ Vitamin Folic Acid. Some 50\% of the US population has one or more mutations in the Methylfolate Reductase (MTHFR) gene, which makes them unable to process sufficient dietary folate into the active methylfolate form needed by the body. People with insufficient methylfolate are at higher risks of ill health [56-59]. SC100+ provides $300 \mathrm{mcg}$ of methyfolate per serving, which is $75 \%$ of the minimum daily requirement.

The ninth component in SC100+ is Methyl B12, which is the methylated active form of vitamin B12. Older people are at risk of B12 deficiency because of poor absorption. Sufficient levels of Methyl B12 promote cellular immunity, cognitive function, and motor nerves [60-62]. SC100+ provides $250 \mathrm{mcg}$ of Methyl B12 per serving, which is $4167 \%$ of the minimum daily requirement to ensure sufficient levels in older individuals.

The tenth component in SC100+ is Vitamin D3, which is the active form of vitamin D. Vitamin D3 is well known to be important in the regulation of calcium in supporting healthy bones and teeth. More recently, Vitamin D3 has been shown to promote overall health. Many older people are deficient in Vitamin D3, which can lead to a greater risk of ill health [63-65]. Vitamin D3 is also reported to reduce all-cause mortality [66-68]. SC100+ provides 1000 IU of Vitamin D3 per serving, which is $250 \%$ of the minimum daily requirement. 
The $10 \mathrm{SC} 100+$ components detailed above are a set of synergistic components that act on a critical number of the longevity targets. In this report, we test SC100+ as a multipath intervention in a small open label clinical study of healthy older adults.

\section{Methods}

\section{SC100+ description}

The SC100+ multipath dietary supplement is a patentpending dietary supplement with the following 10 active compounds present in each capsule: 1) Astragalus membranaceus root extract; 2) Rhodiola rosea root extract; 3) Vaccium Uliginosum fruit extract standardized for resveratrol analogs; 4) Tulsi leaf extract; 5) Pine Bark root extract standardized for 94\% Oligomeric-Proanthocyanidins; 6) L-Theanine; 7) Genistein; 8) Methyl Folate (300 mcg 5MTHF); 9) Methyl B12 (250 mcg Methylcobalamin); and 10) Vitamin D3 (1000 IU). SC100+ capsules were provided by Centagen, Inc.

\section{Study participants and design}

The clinical trial described in this paper was a small open-label pilot study on the effects of SC100+ on health markers in male and female subjects 42 to 79 years of age (mean of 57 years). The needed sample size for some of the markers was calculated based on a smaller pilot study with 5 subjects, wherein blood pressure and cholesterol were measured at baseline and after 6 weeks of treatment. The final trial patient size was determined using an online power analysis calculator for systolic and diastolic blood pressure, HDL Cholesterol, Lung function, and Stress testing. The power analysis showed that a $90 \%$ chance of detecting a $5 \%$ change in Blood pressure and HDL Cholesterol required 13 to 15 patients, while a $5 \%$ change in Lung Function or Stress levels required 5 to 6 patients. Therefore, our goal was a sample size of at least 15 patients without a placebo control. Unfortunately, project funding only allowed for 15 to 16 patients and placebo controls would require almost double our available funding. The open label pilot study was retrospectively registered on Feb. 8, 2017 (NCT03052491).

Sixteen volunteers for the trial were recruited publicly from Los Angeles and San Diego and the actual trial was run March through August of 2016. One subject dropped out in the first week due to unrelated medical problems from doctor-prescribed hormone treatment. The other 15 subjects completed 15 weeks on the SC100 + supplement without any reported side effects.

The selection criteria for the study volunteers consisted of: 1) Excludes subjects younger than 35 years or pregnant women; 2) No history of metastatic cancer, heart attack, or dementia; 3) Currently healthy with no life-threatening diseases; 4) Willing to undergo clinical blood tests and other non-invasive tests at baseline and after taking SC100+; 5) Committed to taking one SC100 + capsule twice daily for the test period; 6) Willing to sign the IRB Research Participant Consent Form.

\section{Subject recruitment and follow-up}

The recruitment period started in mid-February, 2016, and continued through early April of 2016. The first subjects started baseline testing March 12, 2016, while the last subject was baseline tested April 10, 2016. All subjects had completed the final testing at the end of the trial by August 14, 2016. Depending on their schedule, SC100+ supplementation and follow up continued for an average of 15 weeks with a minimum of 13.5 weeks and a maximum of 16.5 weeks. All 15 completed the lab tests as required with the exception of the lung and stress tests that had only 12 subjects complete these specialized tests. To reduce the potential for bias, final testing was done without knowledge of individual baseline test results.

\section{Statistical analysis}

Results are expressed as mean $+/-95 \% \mathrm{t}$-test confidence intervals. Paired two-sided Student $\mathrm{t}$-tests were performed to evaluate the significance of differences between baseline and post $\mathrm{SC100+}$ supplementation values for systolic and diastolic blood pressure, HDL and Total Cholesterol, lung function, stress test, heart rate, and HbA1c levels. A $p$ value of $<0.05$ was considered significant. All statistical analyses were carried out with Microsoft Excel and double checked using the commercial scientific statistics software from GraphPad Software, Inc.

\section{Results}

\section{SC100+ was tested in an open label pilot study}

We have carried out an IRB approved clinical trial using 10 active component multipath formulation described above to treat human volunteers for a period of 15 week duration. The pilot study was an open-labeled field trial on healthy human subjects. Seven females and eight males participated and completed the trial with no reported side effects. The average age of the subjects was 57 with a range of 42 to 79 years. Most subjects were in their 50 s, while 3 subjects were under 52 years of age and 2 subjects were over 70 .

The subjects were tested at baseline and after 15 weeks on SC100+ for the following: systolic and diastolic arterial blood pressure, heart rate, total blood cholesterol, HDL blood cholesterol, stress, lung capacity, and selfrated health survey. For the intervention clinical trial, the subjects were instructed to take one $\mathrm{SC} 100+$ capsule twice daily at breakfast and dinner. During the clinical trial with $\mathrm{SC} 100+$, the subjects were permitted to 
continue taking their prescription drugs and any supplements that they had previously been taking.

Figure 1 shows a flow chart of the clinical trial. Potential subjects were first contacted at youth soccer matches or using the parental email lists of junior soccer players. Twenty subjects expressed interest in joining the trial and were assessed for eligibility. All 20 subjects were deemed eligible. Three of the 20 subjects later declined to participate and one subject moved away and was thus unavailable for testing. The remaining 16 subjects received a 60 day supply of SC100+. One subject dropped out of the trial in the first week due to issues with hormone replacement therapy that was added a few days before starting the SC100+ study. The remaining 15 subjects completed the trial. Tests were performed on the 15 subjects at baseline and after 15 weeks on SC100+. In the case of stress and lung function, only 12 subjects took these two tests, as 3 subjects could not come to the facility with the required specialized equipment needed for stress and lung testing.

\section{SC100+ lowers systolic and diastolic blood pressure}

Ambulatory blood pressure (BP) was measured by sphygmomanometer. Subjects started with a mean BP of
$126 / 81 \mathrm{mmHg}$. Since most of the subjects were over 50 , the average blood pressure of $126 / 81 \mathrm{mmHg}$ at the start of the trial was within the normal range.

Figure 2 shows baseline and after 15 weeks of taking the $\mathrm{SC} 100+$ multipath supplement. SC100+ reduced mean systolic blood pressure (SBP) by $-10.0+/-$ $6.37 \mathrm{mmHg}(P<0.013)$ as shown in Fig. 2a. The SC100+ reduction in diastolic blood pressure (DBP) was -4.6 $+/-4.17 \mathrm{mmHg}(P=0.048)$ as shown in Fig. 2b. Mean $\mathrm{BP}$ was in the normal range at baseline (mean 126/81), but fell to the low normal range (mean 116/76) after 15 weeks of SC100 +.

While $\mathrm{SC} 100+$ is not a treatment for hypertension, Fig. 2 also included drug data from a multicenter, double blind, randomized trial [69] on 132 hypertensive patients (average age of 59 years and 59\% male with starting BP of $143 / 88 \mathrm{mmHg}$ ) treated with the antihypertension codrugs valsartan $80 \mathrm{mg}$ and hydrochlorothiazide $12.5 \mathrm{mg}$ (VH treatment). The $\mathrm{VH}$ co-drug treatment reduction in SBP was $-15.4+/-10.9 \mathrm{mmHg}$ versus the placebo reading of $-0.6+/-7.7 \mathrm{mmHg}(p<0.001)$ as shown in Fig. 2a. The $\mathrm{VH}$ co-drug treatment reduction in DBP was -9.1 $+/-7 \mathrm{mmHg}$ versus the placebo reading of $-0.4+/-$ $5.4 \mathrm{mmHg}(p<0.001)$ as shown in Fig. $2 \mathrm{~b}$.

\section{Open-Label Clinical Flow Diagram}

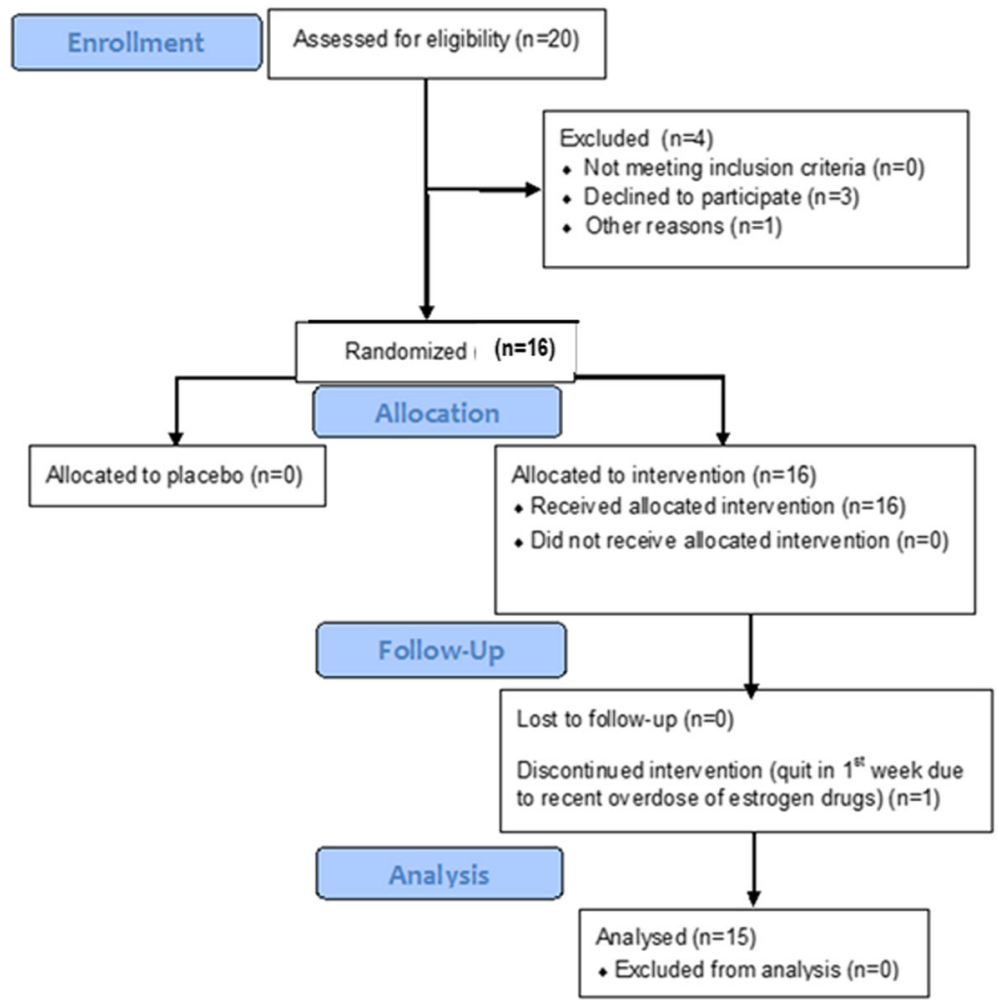

Fig. 1 Participant Clinical Flow Diagram: The flow of subjects through each stage of the SC100+ clinical study is shown in the Clinical Flow Diagram 

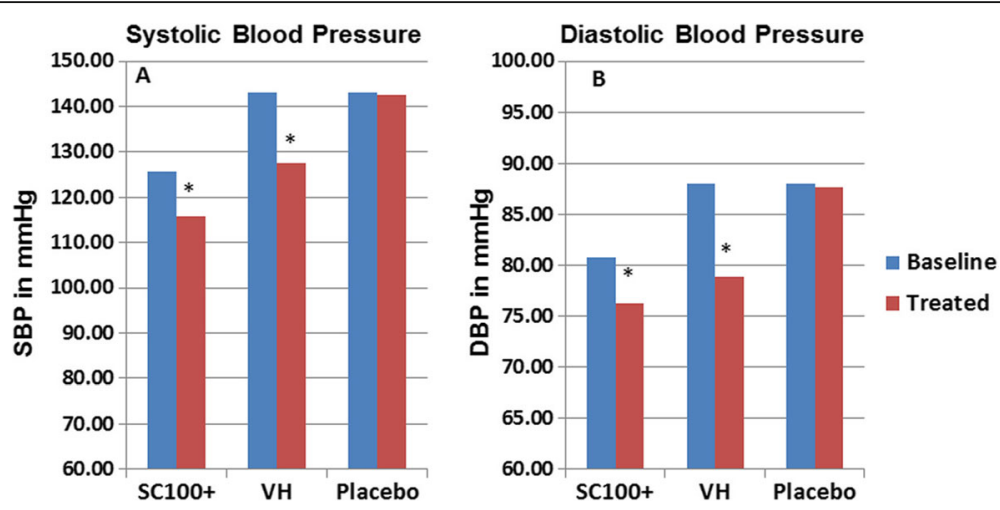

Fig. 2 SC100+ lowers systolic and diastolic blood pressure. Subjects took open-labeled SC100+ for 15 weeks. Systolic Blood Pressure (SBP in A) and Diastolic Blood Pressure (DBP in B) were measured at baseline (blue bars) and after taking SC100+ (red bars). SBP and DBP were in the normal range before and after SC100+. All significant reductions ( $p<0.05$ in paired t tests) in SBP and DBP are designated with a Star. For comparison with hypertensive patients on drugs, the VH (80 mg valsartan $+12.5 \mathrm{mg}$ hydrochlorothiazide) and Placebo samples were from a published multicenter, double blind, randomized trial [69] on 132 hypertensive patients (average age of 59 years and 59\% male with starting BP of 143/88 $\mathrm{mmHg}$ ) treated with VH or a placebo

\section{SC100+ increases HDL cholesterol}

High-Density Lipoprotein (HDL) cholesterol was measured in the clinical subjects on whole blood drawn at baseline and after 15 weeks of SC100+. HDL is the so called "good" cholesterol and higher is better. HDL cholesterol increased significantly from a mean of 61.4 to $69.3 \mathrm{mg} / \mathrm{dL}(7.9+/-2.90 \mathrm{mg} / \mathrm{dL}, p=0.005)$ with SC100 +. Thus, 15 weeks of SC100+ led to a highly significant $12.9 \%$ increase in HDL Cholesterol (Fig. 3) for subjects with baseline HDL cholesterol already in the normal range. As a comparison to the placebo-controlled clinical trial with the statin Atovastatin (Atorvas Fig. 3),
6 weeks of treatment at $10 \mathrm{mg} /$ day dose increases HDL Cholesterol by $3.5 \%$, which is not significantly different from the placebo increases in HDL Cholesterol of 2.3\% [70]. Fig. 3 also includes a comparison to the HDL Cholesterol increase found in a clinical trial with Extended Release Niacin (ERN in Fig. 3), which raised HDL Cholesterol $18 \%(p<0.001)$ in this trial [71].

\section{No significant change in Total cholesterol or blood $\mathrm{HbA1c}$ levels with $\mathrm{SC} 100+$}

Total Cholesterol (TC) and blood glycosylated hemoglobin (HbA1c) levels were also tested in the

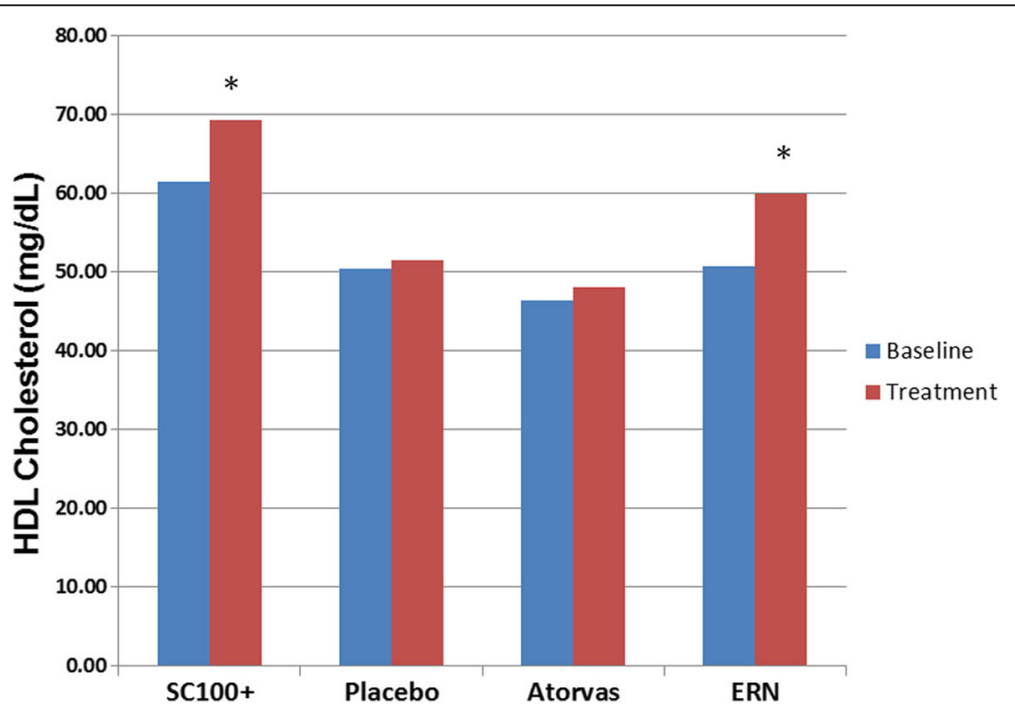

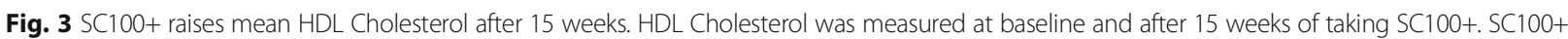
raised mean $\mathrm{HDL}$ Cholesterol 12.8\% ( $p<0.005$ in paired t tests). While SC100+ is not a treatment for low HDL Cholesterol, Fig. 3 also compares SC100+ to the effects of treatment with the drugs Atorvastatin (Atorvas at $10 \mathrm{mg} /$ day for 6 weeks, $N=64)$ in a placebo-controlled $(N=22)$ clinical trial [70], and Extended Release Niacin (ERN at $1500 \mathrm{mg} /$ day for 6 weeks, $N=27$ ), which is taken from a placebo-ERN crossover clinical trial [71]. All stared results are significant with $p<0.05$ 
subjects at baseline and after 15 weeks of SC100+. Table 1 shows that mean Total Cholesterol did not change significantly with 15 weeks of SC100+ (202 mg/ $\mathrm{dL}$ to $206 \mathrm{mg} / \mathrm{dL}, p=0.582$ ) and are in the normal range. Table 1 also shows that mean blood percentage of HbA1c levels did not change significantly with 15 weeks of SC100+ $(5.84 \%$ to $5.73 \%, p=0.488)$.

Subjects were tested for Total Cholesterol (TC) in mg/ $\mathrm{dL}$ and blood glycosylated hemoglobin HbA1c levels as percent of total hemoglobin at baseline (column 2) and after taking SC100+ for 15 weeks (column 4). The TC and HbA1c Standard Deviations (SD) for baseline and after taking SC100+ are shown in the third and fifth column respectively. The sixth column shows the difference between the means at baseline and after taking SC100+ and the seventh column shows the paired t test significance of these mean differences.

\section{SC100+ enhances lung function}

Lung function was also measured in the clinical subjects using an Electronic Peak Expiratory Flow (PEF) Meter for lung spirometry to check peak force breath flow from the lung. PEF was measured on subjects at baseline and after 15 weeks of SC100+. The average PEF of all subjects tested increased significantly from a mean of $452 \mathrm{l} / \mathrm{min}$ to $527 \mathrm{l} / \mathrm{min}$, which is a $16.6 \%$ increase in lung function (Fig. 4). This represents a highly significant mean gain of $74.9+/-37.5 \mathrm{l} / \mathrm{min}(p=0.001)$ for the whole population tested $(N=12)$. When broken down into gender differences after taking $\mathrm{SC} 100+$, females gained $21.4 \%$ in function $(77.8+/-85.8 \mathrm{l} / \mathrm{min}, p=0.066)$, which trended higher but was not significant with the small subgroup size of $N=5$ ). Males gained $14.2 \%$ in function $(73.1+/-52.2, p=0.014)$, which was significant with the larger subgroup size of $N=7$.

\section{SC100+ reduces apparent stress levels and trends to lower heart rates}

One objective measure of stress is reflected in measures of the variations in the interval between heart beats, which is called Heart Rate Variability (HRV). We measured the HRV in subjects at baseline and after 15 weeks of taking SC100+ (Stress Marker in Table 2) and found an apparent reduced stress level of $-24.8 \%$. This translates into a significant HRV reduction of $-76.6+/-42(p$ $=0.017$ ). Mean heart rate (pulse) also trended lower with 15 weeks of taking $\mathrm{SC} 100+(-2.60+/-3.74 \mathrm{bpm}, p=$

Table 1 SC100+ has no significant effects on Total Cholesterol or HbA1c levels

\begin{tabular}{lllllll}
\hline Marker & Baseline & SD & SC100+ & SD & Difference & Significance \\
\hline TC & 202 & 36.1 & 206 & 34.0 & 4 & $p=0.582$ \\
HbA1C & 5.84 & 1.05 & 5.73 & 0.69 & -0.11 & $p=0.488$ \\
\hline
\end{tabular}

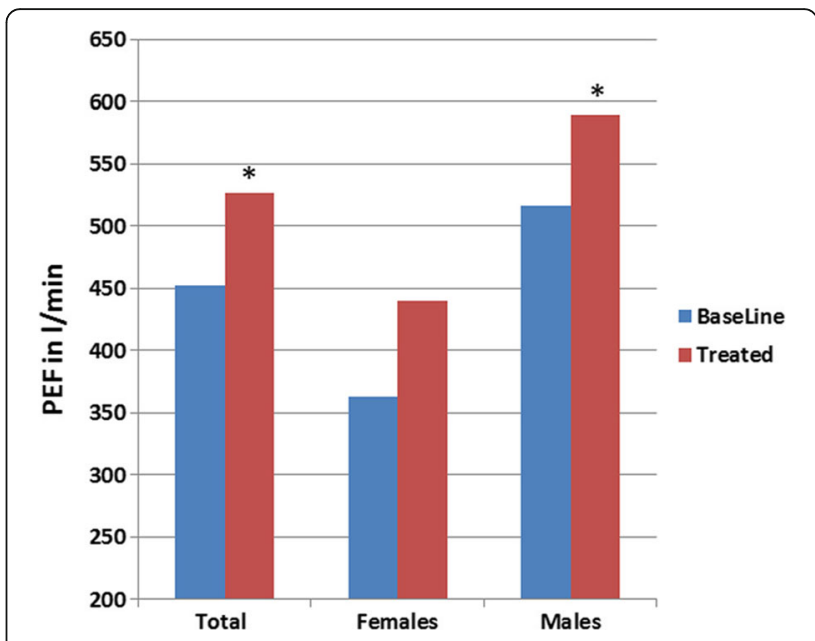

Fig. 4 SC100+ supplement significantly raises mean PEF. SC100+ raised mean total Peak Expiratory Flow (PEF) by $16.6 \%(p=0.001$ in paired $t$ tests). If each sex is taken separately, SC100+ raised mean PEF by $21.4 \%$ $(p=0.066)$ for Females $(N=5)$ and $14.2 \%(p=0.014)$ for Males $(N=7)$

0.178), but the difference was not significant (Heart Rate in Table 2).

Subjects were measured for heart rate variability (HRV) as an objective stress marker at baseline and after taking 15 weeks of SC100+. HRV was measured via finger photo-plethysmography during a 5-min rest period $[72,73]$. The Stress (HRV) of Table 2 shows the mean stress level for all subjects at baseline and after taking $\mathrm{SC} 100+$. Mean Heart Rate in beats per minute (bpm) is shown in row 3 at baseline and after $\mathrm{SC} 100+$. Stress and Heart Rate Standard Deviations (SD) at baseline and post $\mathrm{SC} 100+$ are shown in the third and fifth column respectively. The difference trend and significance (paired t test) of the Stress and Heart Rate changes after taking SC100+ are shown in columns 6 and 7 respectively.

\section{Discussion}

The composite multipath $\mathrm{SC100+} \mathrm{supplement} \mathrm{has} \mathrm{sig-}$ nificant effects on blood pressure. While SC100+ is not a treatment for hypertension, the reduction in BP by the SC100+ supplement (Fig. 2) was significant, and even approaches the levels observed in the $\mathrm{VH}$ co-drug treatment with hypertensive drugs valsartan (angiotensin II receptor antagonist) and hydrochlorothiazide (a diuretic). However, the comparison with known drugs is inexact, as the subjects in our SC100+ clinical study typically had baseline blood pressure in the normal

Table 2 SC100+ lowers key marker of stress and trends to lowered heart rate

\begin{tabular}{lllllll}
\hline Marker & Baseline & SD & SC100+ & SD & Difference & Significance \\
\hline Stress & 308 & 99 & 232 & 50 & $-24.8 \%$ & $p=0.017$ \\
Heart Rate & 68.8 & 15.8 & 66.3 & 10.8 & $-3.8 \%$ & $p=0.178$ \\
\hline
\end{tabular}


range for their age, which was clearly not the case in the $\mathrm{VH}$ co-drug treated hypertensive patients. Thus, the SC100+ supplement appears to take subjects with BP in the higher normal range for adults over 50 (mean 126/ $81 \mathrm{mmHg}$ ) to low youthful levels (mean 116/66 mmHg). BP levels at or below $120 / 80 \mathrm{mmHg}$ in midlife are associated with longer life and better quality of life [72]. Moreover, unlike the known hypertensive drugs, SC100+ appeared to have a balancing effect on 4 subjects with very low $\mathrm{BP}$ at baseline (mean of 100/68 $\mathrm{mmHg}$ at baseline to $106 / 71 \mathrm{mmHg}$ with supplement). Since BP is an important indicator of overall health and longer life [74], these BP results support our hypothesis that SC100+ promotes overall health and life expectancy.

Treating with the SC100+ dietary supplement led to a significant $12.9 \%$ increase in HDL Cholesterol (Fig. 3). However, it is important to note that all of the clinical subjects had normal levels of Total Cholesterol (202 +/$18.6 \mathrm{mg} / \mathrm{dL}$ ) and high normal levels of HDL Cholesterol $(61+/-6.8 \mathrm{mg} / \mathrm{dL})$ at baseline. The increase in normal levels of HDL Cholesterol by $\mathrm{SC} 100+$ is important because people with higher levels of HDL have lower risks of ill health, frailty, and total mortality, while having higher physical performance levels and cognition [75-78]. Moreover, while ERN niacin treatment raises HDL Cholesterol significantly in subjects with chronically low HDL Cholesterol, ERN has significant adverse effects and has failed in clinical trials to decrease mortality risks $[79,80]$. Our clinical data showed that HDL Cholesterol levels were significantly increased in subjects treated with $\mathrm{SC} 100+$ provides further suggestive data to support our hypothesis that $\mathrm{SC} 100+$ promotes overall health and life expectancy.

Lung function was also measured in the study subjects using lung spirometry to check peak force breath flow from the lung. Peak Expiratory Flow (PEF) was measured on subjects at baseline and after 15 weeks of SC100+. The average PEF of all subjects tested increased significantly from a mean of $452 \mathrm{l} / \mathrm{min}$ to $527 \mathrm{l} / \mathrm{min}$ (up $75+/-37.5 \mathrm{l}$ / min, $p=0.001$ ), which is a $16.6 \%$ increase in lung function (Fig. 4). Impaired pulmonary function has been linked to greater risks of ill health and all-cause mortality [81]. In addition to being a reliable measure of pulmonary function, PEF has been shown to be a valid measure of overall health status and all-cause mortality [82-86].

Stress was also measured in the clinical subjects using Heart Rate Variability (HRV), which has been reported by several clinical studies to be a strong marker of stress [87-90]. HRV as a measure of stress was significantly reduced $24.8 \%(p=0.017$, Table 2$)$. Stress is very strong predictor of overall health and all-cause mortality [91-94]. Moreover, centenarians have reduced low frequency HRV readings [95] compared to a normal aged population over 75 years of age and stress is also markedly lower in centenarians [96-98].
Limitations of this preliminary study are easy to identify. First, this was an open-label clinical study without a placebo test group. In practice, many of the variables testing significant in the study were objective tests such as lung function, HDL Cholesterol, and HRV tests, which typically test very low in placebo tests. Moreover, the SC100+ supplement was accurately labeled as a commercial stem cell enhancer product (Stem Cell 100+), so the subjects in the trial had little reason to expect changes in blood pressure, stress levels, HDL Cholesterol, lung function, or overall health over the short period of 15 weeks.

A second limitation of the preliminary study is the small size of 15 subjects. A larger trial would be needed to have better confidence in these promising results. Despite the small size, both genders were represented and all ages in the $40 \mathrm{~s}, 50 \mathrm{~s}, 60 \mathrm{~s}$, and $70 \mathrm{~s}$ were part of the trial and showed positive trends with respect to the overall health and life expectancy markers.

\section{Conclusions}

Results of this study show that a composite multipath SC100+ supplement has striking effects on the health and vitality of healthy subjects in this small clinical study. Targeting simultaneously multiple aging pathways significantly reduced blood pressure and stress, while significantly increasing HDL Cholesterol levels and lung capacity. Targeting multiple critical aging pathways with a multipath dietary supplement is a novel alternative strategy to promote overall health.

\section{Abbreviations \\ BP: Blood pressure; DBP: Diastolic blood pressure; ERN: Extended release niacin; HbA1c: Glycosylated hemoglobin; HDL: High-density lipoprotein; HRV: Heart rate variability; PEF: Peak expiratory flow; SBP: Systolic blood pressure; SC100+: Stem Cell 100+; TC: Total cholesterol; VH: Valsartan + hydrochlorothiazide}

\section{Acknowledgements}

Med Tech John Still assisted YS with some of the blood lab testing.

\section{Funding}

Supplies and services for the clinical trial and article processing charges are funded by Centagen, Inc. Centagen had no role in the study design, data collection, data analysis, or preparation of the manuscript.

\section{Availability of data and materials}

The dataset generated and analyzed from the 15 individual subjects during the current study are included in the current study as a PDF supporting file (see Clinical Raw Data). As for the SC100+ dietary supplement, contact info@Centagen.com for SC100+ research samples or purchase the commercial version of SC100+ (Stem Cell 100+) online at www.Centagen.com .

\section{Author's contributions}

YS collected blood samples from all subjects. YS was responsible for most lab assays on the blood samples. YS and BV performed the blood pressure and heart rate tests. BV performed the stress tests and the lung function tests. BV analyzed the data and was the principle writer of the manuscript. Both authors read and approved the manuscript. 


\section{Ethics approval and consent to participate}

The clinical trial (IRCM-2016-091) was approved for up to 20 subjects by the Institutional Review Board (IRB) in the Institute of Regenerative and Cellular Medicine on Feb. 25, 2016. Written informed consent for the clinical trial was obtained from all volunteers prior to baseline testing and the informed consent forms were approved by the IRB. The selection of subjects for the study adhered to $\mathrm{NIH}$ guidelines.

\section{Consent for publication}

Not applicable

\section{Competing interests}

$\mathrm{BV}$ is a cofounder, unpaid consultant, and equity holder in Centagen. YS does not have any declared competing interests. This does not alter the authors' adherence to the policies on sharing data or materials.

\section{Publisher's Note}

Springer Nature remains neutral with regard to jurisdictional claims in published maps and institutional affiliations.

\section{Author details}

'Centagen Inc., 637 S. Broadway St., Ste. B-206, Boulder, CO 80305, USA.

${ }^{2}$ Medical Lab Consultants, 3507 Beethoven St, Los Angeles, CA 90066, USA.

\section{Received: 5 September 2017 Accepted: 3 November 2017}

Published online: 14 November 2017

\section{References}

1. Giaimo S. Evolution of aging through reduced demographic stochasticity an extension of the pleiotropy theory to finite populations. Ecol Evol. 2014;4:167-73.

2. Partridge $\mathrm{L}$, Barton $\mathrm{NH}$. Evolution of aging: testing the theory using drosophila. Genetica. 1993;91:89-98.

3. Villeponteau B, Matsagas K, Nobles AC, Rizza C, Horwitz M, Benford G, Mockett RJ. Herbal supplement extends life span under some environmental conditions and boosts stress resistance. PLoS One. 2015:10:e0119068.

4. Akunuru S, Geiger H. Aging, Clonality, and rejuvenation of hematopoietic stem cells. Trends Mol Med. 2016;22:701-12.

5. Nurkovic J, Volarevic V, Lako M, Armstrong L, Arsenijevic N, Stojkovic M. Aging of stem and progenitor cells: mechanisms, impact on therapeutic potential, and rejuvenation. Rejuvenation Res. 2016;19:3-12.

6. Ocampo A, Reddy P, Martinez-Redondo P, Platero-Luengo A, Hatanaka F, Hishida T, Li M, Lam D, Kurita M, Beyret E, et al. In vivo amelioration of ageassociated hallmarks by partial reprogramming. Cell. 2016;167:1719-33. e1712

7. Yang F, Yan G, Li Y, Han Z, Zhang L, Chen S, Feng C, Huang Q, Ding F, Yu Y, et al. Astragalus polysaccharide attenuated iron overload-induced dysfunction of Mesenchymal stem cells via suppressing mitochondrial ROS. Cell Physiol Biochem. 2016;39:1369-79.

8. Shen B, Chen L, Zhou K, Jin KK. Effects of astragalus and Angelica on bone marrow stem cells proliferation and VEGF protein expression in vitro. Zhongguo Gu Shang. 2011:24:652-5.

9. Yu Q, Bai YS, Lin J. Effect of Astragalus injection combined with mesenchymal stem cells transplantation for repairing the spinal cord injury in rats. Zhongguo Zhong Xi Yi Jie He Za Zhi. 2010;30:393-7.

10. Xu CJ, Jian XC, Guo F, Gao QP, Peng JY, Xu XP. Effect of astragalus polysaccharides on the proliferation and ultrastructure of dog bone marrow stem cells induced into osteoblasts in vitro. Hua Xi Kou Qiang Yi Xue Za Zhi. 2007;25:432-6.

11. Wang YJ, Yu YR. Protective effects of Astragalus Membranaceus on free fatty acid-induced vascular endothelial cell dysfunction. Sichuan Da Xue Xue Bao Yi Xue Ban. 2011:42:48-51.

12. Zhang BQ, Hu SJ, Qiu LH, Shan QX, Sun J, Xia Q, Bian K. Diphasic effects of Astragalus Membranaceus BUNGE (Leguminosae) on vascular tone in rat thoracic aorta. Biol Pharm Bull. 2005;28:1450-4

13. Hao Y, Qiu QY, Wu J. Effect of Astragalus polysaccharides in promoting neutrophil-vascular endothelial cell adhesion and expression of related adhesive molecules. Zhongguo Zhong Xi Yi Jie He Za Zhi. 2004;24:427-30.

14. Shi FS, Yang ZG, Di GP. Effect of Astragalus saponin on vascular endothelial cell and its function in burn patients. Zhongguo Zhong Xi Yi Jie He Za Zhi. 2001;21:750-1.
15. Song QH, Xu RM, Zhang QH, Shen GQ, Ma M, Zhao XP, Guo YH, Wang Y. Combined effects of astragalus soup and persistent Taiji boxing on improving the immunity of elderly women. Int J Clin Exp Med. 2014;7:1873-7.

16. Kallon S, Li X, Ji J, Chen C, Xi Q, Chang S, Xue C, Ma J, Xie Q, Zhang Y. Astragalus polysaccharide enhances immunity and inhibits H9N2 avian influenza virus in vitro and in vivo. J Anim Sci Biotechnol. 2013:4:22.

17. Li SP, Zhao XJ, Wang JY. Synergy of Astragalus polysaccharides and probiotics (lactobacillus and Bacillus Cereus) on immunity and intestinal microbiota in chicks. Poult Sci. 2009;88:519-25.

18. Wu J, Wang YX, Su WL, Zhu WX, Lu JW, Li ZK. Effect of astragalus injection on serious abdominal traumatic patients' cellular immunity. Chin J Integr Med. 2006;12:29-31.

19. Lu L, Huang YF, Chen DX, Wang M, Zou YC, Wan H, Wei LB. Astragalus polysaccharides decrease muscle wasting through Akt/mTOR, ubiquitin proteasome and autophagy signalling in 5/6 nephrectomised rats. J Ethnopharmacol. 2016;186:125-35.

20. Cropley M, Banks AP, Boyle J. The effects of Rhodiola Rosea L. extract on anxiety, stress, cognition and other mood symptoms. Phytother Res. 2015;29:1934-9.

21. Edwards D, Heufelder A, Zimmermann A. Therapeutic effects and safety of Rhodiola Rosea extract WS(R) 1375 in subjects with life-stress symptomsresults of an open-label study. Phytother Res. 2012;26:1220-5.

22. Chen C, Song J, Chen M, Li Z, Tong X, Hu H, Xiang Z, Lu C, Dai F. Rhodiola Rosea extends lifespan and improves stress tolerance in silkworm, Bombyx Mori. Biogerontology. 2016;17:373-81.

23. Bayliak MM, Burdyliuk NI, Izers'ka LI, Lushchak VI. Concentration-dependent effects of Rhodiola Rosea on long-term survival and stress resistance of yeast Saccharomyces Cerevisiae: the involvement of YAP 1 and MSN2/4 regulatory proteins. Dose Response. 2014;12:93-109.

24. Schriner SE, Coskun V, Hogan SP, Nguyen CT, Lopez TE, Jafari M. Extension of drosophila lifespan by Rhodiola Rosea depends on dietary carbohydrate and caloric content in a simplified diet. J Med Food. 2016;19:318-23.

25. Gospodaryov DV, Yurkevych IS, Jafari M, Lushchak VI, Lushchak OV. Lifespan extension and delay of age-related functional decline caused by Rhodiola Rosea depends on dietary macronutrient balance. Longev Healthspan. 2013;2:5.

26. Rimando AM, Nagmani R, Feller DR, Yokoyama W. Pterostilbene, a new agonist for the peroxisome proliferator-activated receptor alpha-isoform, lowers plasma lipoproteins and cholesterol in hypercholesterolemic hamsters. J Agric Food Chem. 2005;53:3403-7.

27. Cheng Y, Di S, Fan C, Cai L, Gao C, Jiang P, Hu W, Ma Z, Jiang S, Dong Y, et al. SIRT1 activation by pterostilbene attenuates the skeletal muscle oxidative stress injury and mitochondrial dysfunction induced by ischemia reperfusion injury. Apoptosis. 2016;21:905-16.

28. Guo Y, Zhang L, Li F, Hu CP, Zhang Z. Restoration of sirt1 function by pterostilbene attenuates hypoxia-reoxygenation injury in cardiomyocytes. Eur J Pharmacol. 2016;776:26-33.

29. Zhang $Y$, Zhang Y. Pterostilbene, a novel natural plant conduct, inhibits high fat-induced atherosclerosis inflammation via NF-kappaB signaling pathway in toll-like receptor 5 (TLR5) deficient mice. Biomed Pharmacother. 2016:81:345-55.

30. Li J, Ruzhi D, Hua X, Zhang L, Lu F, Coursey TG, Pflugfelder SC, Li DQ. Blueberry component Pterostilbene protects corneal epithelial cells from inflammation via anti-oxidative pathway. Sci Rep. 2016;6:19408.

31. Wang $C$, Sun H, Song Y, Ma Z, Zhang G, Gu X, Zhao L. Pterostilbene attenuates inflammation in rat heart subjected to ischemia-reperfusion: role of TLR4/NF-kappaB signaling pathway. Int J Clin Exp Med. 2015;8:1737-46.

32. Goel A, Kumar S, Singh DK, Bhatia AK. Wound healing potential of Ocimum Sanctum Linn. With induction of tumor necrosis factor-alpha. Indian J Exp Biol. 2010;48:402-6.

33. Shetty S, Udupa S, Udupa L. Evaluation of antioxidant and wound healing effects of alcoholic and aqueous extract of Ocimum Sanctum Linn in rats. Evid Based Complement Alternat Med. 2008;5:95-101.

34. Osuagwu FC, Oladejo OW, Imosemi IO, Adewoyin BA, Aiku A, Ekpo OE, Oluwadara OO, Ozegbe PC, Akang EE. Wound healing activities of methanolic extracts Ocimum Gratissimum leaf in Wistar rats - a preliminary study. Afr J Med Med Sci. 2004;33:23-6.

35. Dharmani P, Kuchibhotla VK, Maurya R, Srivastava S, Sharma S, Palit G. Evaluation of anti-ulcerogenic and ulcer-healing properties of Ocimum Sanctum Linn. J Ethnopharmacol. 2004;93:197-206.

36. Jyoti S, Satendra S, Sushma S, Anjana T, Shashi S. Antistressor activity of Ocimum Sanctum (Tulsi) against experimentally induced oxidative stress in rabbits. Methods Find Exp Clin Pharmacol. 2007;29:411-6. 
37. Jothie Richard E, Illuri R, Bethapudi B, Anandhakumar S, Bhaskar A, Chinampudur Velusami C, Mundkinajeddu D, Agarwal A. Anti-stress activity of Ocimum Sanctum: possible effects on hypothalamic-pituitary-adrenal Axis. Phytother Res. 2016;30:805-14.

38. Gupta D, Bhaskar DJ, Gupta RK, Karim B, Jain A, Singh R, Karim W. A randomized controlled clinical trial of Ocimum Sanctum and chlorhexidine mouthwash on dental plaque and gingival inflammation. J Ayurveda Integr Med. 2014;5:109-16.

39. Ohkita M, Kiso Y, Matsumura Y. Pharmacology in health foods: improvement of vascular endothelial function by French maritime pine bark extract (Flavangenol). J Pharmacol Sci. 2011;115:461-5.

40. Kwak CJ, Kubo E, Fujii K, Nishimura Y, Kobuchi S, Ohkita M, Yoshimura M, Kiso $Y$, Matsumura Y. Antihypertensive effect of French maritime pine bark extract (Flavangenol): possible involvement of endothelial nitric oxidedependent vasorelaxation. J Hypertens. 2009;27:92-101.

41. Jiang $Y$, Han W, Shen T, Wang MH. Antioxidant activity and protection from DNA damage by water extract from pine (Pinus Densiflora) bark. Prev Nutr Food Sci. 2012;17:116-21.

42. McGrath KC, Li XH, McRobb LS, Heather AK. Inhibitory effect of a French maritime pine bark extract-based nutritional supplement on TNF-alphainduced inflammation and oxidative stress in human coronary artery endothelial cells. Evid Based Complement Alternat Med. 2015;2015:260530.

43. Sumathi T, Asha D, Nagarajan G, Sreenivas A, Nivedha R. L-Theanine alleviates the neuropathological changes induced by PCB (Aroclor 1254) via inhibiting upregulation of inflammatory cytokines and oxidative stress in rat brain. Environ Toxicol Pharmacol. 2016;42:99-117.

44. White DJ, de Klerk S, Woods W, Gondalia S, Noonan C, Scholey AB. Antistress, Behavioural and Magnetoencephalography effects of an L-Theaninebased nutrient drink: a randomised, double-blind, placebo-controlled, crossover trial. Nutrients. 2016;8(1). doi:10.3390/nu8010053.

45. Ceremuga TE, Martinson S, Washington J, Revels R, Wojcicki J, Crawford D, Edwards R, Kemper JL, Townsend WL, Herron GM, et al. Effects of L-theanine on posttraumatic stress disorder induced changes in rat brain gene expression. ScientificWorldJournal. 2014;2014:419032.

46. Tian X, Sun L, Gou L, Ling X, Feng Y, Wang L, Yin X, Liu Y. Protective effect of I-theanine on chronic restraint stress-induced cognitive impairments in mice. Brain Res. 2013;1503:24-32.

47. Kimura K, Ozeki M, Juneja LR, Ohira H. L-Theanine reduces psychological and physiological stress responses. Biol Psychol. 2007;74:39-45.

48. Takeda A, Sakamoto K, Tamano H, Fukura K, Inui N, Suh SW, Won SJ, Yokogoshi $H$. Facilitated neurogenesis in the developing hippocampus after intake of theanine, an amino acid in tea leaves, and object recognition memory. Cell Mol Neurobiol. 2011;31:1079-88

49. Zarse K, Jabin S, Ristow M. L-Theanine extends lifespan of adult Caenorhabditis Elegans. Eur J Nutr. 2012;51:765-8.

50. Unno K, Fujitani K, Takamori N, Takabayashi F, Maeda K, Miyazaki H, Tanida N, Iguchi K, Shimoi K, Hoshino M. Theanine intake improves the shortened lifespan, cognitive dysfunction and behavioural depression that are induced by chronic psychosocial stress in mice. Free Radic Res. 2011;45:966-74.

51. Chau MN, El Touny LH, Jagadeesh S, Banerjee PP. Physiologically achievable concentrations of genistein enhance telomerase activity in prostate cancer cells via the activation of STAT3. Carcinogenesis. 2007;28:2282-90,

52. Valles SL, Dolz-Gaiton P, Gambini J, Borras C, Lloret A, Pallardo FV, Vina J. Estradiol or genistein prevent Alzheimer's disease-associated inflammation correlating with an increase PPAR gamma expression in cultured astrocytes. Brain Res. 2010:1312:138-44.

53. Lee KY, Kim JR, Choi HC. Genistein-induced LKB1-AMPK activation inhibits senescence of VSMC through autophagy induction. Vasc Pharmacol. 2016;81:75-82

54. Prietsch RF, Monte LG, da Silva FA, Beira FT, Del Pino FA, Campos VF, Collares T, Pinto LS, Spanevello RM, Gamaro GD, Braganhol E. Genistein induces apoptosis and autophagy in human breast MCF-7 cells by modulating the expression of proapoptotic factors and oxidative stress enzymes. Mol Cell Biochem. 2014;390:235-42.

55. Lee EB, Ahn D, Kim BJ, Lee SY, Seo HW, Cha YS, Jeon H, Eun JS, Cha DS, Kim DK. Genistein from Vigna Angularis extends lifespan in Caenorhabditis Elegans. Biomol Ther (Seoul). 2015;23:77-83.

56. Cui T. MTHFR C677T mutation increased the risk of ischemic stroke, especially in large-artery atherosclerosis in adults: an updated meta-analysis from 38 researches. Int J Neurosci. 2016;126:10-9.

57. Chen $Q$, Sun $Y$, Zhang $L$, Deng $K$, Xia H, Xing H, Xiang Y, Ran B, Zhang $M$, Xu X, Fu W. Detection of C677T mutation of MTHFR in subject with coronary heart disease by hairpin probe with enzymatic color on microarray. Biosens Bioelectron. 2011;28:84-90.

58. Dedoussis GV, Panagiotakos DB, Pitsavos C, Chrysohoou C, Skoumas J, Choumerianou D, Stefanadis C, Group AS. An association between the methylenetetrahydrofolate reductase (MTHFR) C677T mutation and inflammation markers related to cardiovascular disease. Int J Cardiol. 2005;100:409-14.

59. Payne DA, Chamoun AJ, Seifert SL, Stouffer GA. MTHFR 677 C $\rightarrow>$ T mutation: a predictor of early-onset coronary artery disease risk. Thromb Res. 2001;103:275-9.

60. Hendren RL, James SJ, Widjaja F, Lawton B, Rosenblatt A, Bent S. Randomized, placebo-controlled trial of methyl B12 for children with autism. J Child Adolesc Psychopharmacol. 2016;26(9):774-83.

61. Tamura J, Kubota K, Murakami H, Sawamura M, Matsushima T, Tamura T, Saitoh T, Kurabayshi H, Naruse T. Immunomodulation by vitamin B12: augmentation of CD8+ T lymphocytes and natural killer (NK) cell activity in vitamin B12deficient patients by methyl-B12 treatment. Clin Exp Immunol. 1999:116:28-32.

62. Yamazaki K, Oda K, Endo C, Kikuchi T, Wakabayashi T. Methylcobalamin (methyl-B12) promotes regeneration of motor nerve terminals degenerating in anterior gracile muscle of gracile axonal dystrophy (GAD) mutant mouse. Neurosci Lett. 1994:170:195-7.

63. Mojto V, Kolcunova M, Rausova Z, Chrenova J, Dedik L. The nonskeletal effects of vitamin D3 and the threshold limit associated with the risk of health complications. Bratisl Lek Listy. 2016;117:133-6.

64. Hollis BW, Marshall DT, Savage SJ, Garrett-Mayer E, Kindy MS, Gattoni-Celli S. Vitamin D3 supplementation, low-risk prostate cancer, and health disparities. J Steroid Biochem Mol Biol. 2013;136:233-7.

65. Baeke F, Etten EV, Overbergh L, Mathieu C. Vitamin D3 and the immune system: maintaining the balance in health and disease. Nutr Res Rev. 2007;20:106-18.

66. Jennersjo P, Guldbrand H, Bjorne S, Lanne T, Fredrikson M, Lindstrom T, Wijkman $\mathrm{M}$, Ostgren CJ, Nystrom FH. A prospective observational study of all-cause mortality in relation to serum 25-OH vitamin D3 and parathyroid hormone levels in patients with type 2 diabetes. Diabetol Metab Syndr. 2015;7:53.

67. Fletcher $\mathrm{RH}$. Review: vitamin D3 supplementation may reduce mortality in adults; vitamin D2 does not. Ann Intern Med. 2014;161:JC5

68. Ralph R, Peter JV, Chrispal A, Zachariah A, Dian J, Sebastian T, Venkatesh B, Thomas K. Supraphysiological 25-hydroxy vitamin D3 level at admission is associated with illness severity and mortality in critically ill patients. J Bone Miner Metab. 2015;33:239-43.

69. Vaisse B, Ghobrial H, Vaur L, Poncelet P, Asmar R, Herpin D, Mallion JM. Antihypertensive effect of valsartan $80 \mathrm{mg}$ and hydrochlorothiazide $12.5 \mathrm{mg}$ evaluated by ambulatory blood pressure monitoring. Arch Mal Coeur Vaiss. 2001;94:907-12.

70. Rosenson RS, Otvos JD, Hsia J. Effects of rosuvastatin and atorvastatin on LDL and HDL particle concentrations in patients with metabolic syndrome: a randomized, double-blind, controlled study. Diabetes Care. 2009:32:1087-91.

71. Yadav R, Liu Y, Kwok S, Hama S, France M, Eatough R, Pemberton P, Schofield J, Siahmansur TJ, Malik R, et al. Effect of extended-release niacin on high-density lipoprotein (HDL) functionality, lipoprotein metabolism, and mediators of vascular inflammation in Statin-treated patients. J Am Heart Assoc. 2015:4:e001508.

72. Linder JR, Stauss HM, Gindes H, Pierce GL, Von Bergen NH, Haynes WG, Fiedorowicz JG. Finger volume pulse waveforms facilitate reliable assessment of heart rate variability, but not blood pressure variability or baroreflex function. BMC Cardiovasc Disord. 2014:14:180.

73. Selvaraj N, Jaryal A, Santhosh J, Deepak KK, Anand S. Assessment of heart rate variability derived from finger-tip photoplethysmography as compared to electrocardiography. J Med Eng Technol. 2008;32:479-84.

74. Strandberg AY, Strandberg TE, Stenholm S, Salomaa W, Pitkala KH, Tilvis RS. Low midlife blood pressure, survival, comorbidity, and health-related quality of life in old age: the Helsinki businessmen study. J Hypertens. 2014:32:1797-804.

75. Atzmon G, Gabriely I, Greiner W, Davidson D, Schechter C, Barzilai N. Plasma $\mathrm{HDL}$ levels highly correlate with cognitive function in exceptional longevity. J Gerontol A Biol Sci Med Sci. 2002:57:M712-5.

76. Barter P. HDL: a recipe for longevity. Atheroscler Suppl. 2004;5:25-31.

77. Laks R, Araujo LM. Almada Filho Cde M, Cendoroglo MS: the importance of HDL-C and CRP in cardiovascular risk evaluation in longevous elderly individuals. Einstein (Sao Paulo). 2011:9:397-403.

78. Landi F, Russo A, Cesari M, Pahor M, Bernabei R, Onder G. HDL-cholestero and physical performance: results from the ageing and longevity study in the sirente geographic area (ilSIRENTE study). Age Ageing. 2007;36:514-20.

79. Mani P, Rohatgi A. Niacin therapy, HDL cholesterol, and cardiovascular disease: is the HDL hypothesis defunct? Curr Atheroscler Rep. 2015;17:43. 
80. Masana L, Cabre A, Heras M, Amigo N, Correig X, Martinez-Hervas S, Real JT, Ascaso JF, Quesada H, Julve J, et al. Remarkable quantitative and qualitative differences in $\mathrm{HDL}$ after niacin or fenofibrate therapy in type 2 diabetic patients. Atherosclerosis. 2015;238:213-9.

81. Waheed S, Chaves PH, Gardin JM, Cao JJ. Cardiovascular and mortality outcomes in the elderly with impaired cardiac and pulmonary function: the cardiovascular health study (CHS). J Am Heart Assoc. 2015;4

82. Fragoso CA, Gahbauer EA, Van Ness PH, Concato J, Gill TM. Peak expiratory flow as a predictor of subsequent disability and death in community-living older persons. J Am Geriatr Soc. 2008;56:1014-20.

83. Roberts MH, Mapel DW. Limited lung function: impact of reduced peak expiratory flow on health status, health-care utilization, and expected survival in older adults. Am J Epidemiol. 2012;176:127-34.

84. Cook NR, Evans DA, Scherr PA, Speizer FE, Taylor JO, Hennekens CH. Peak expiratory flow rate and 5 -year mortality in an elderly population. Am J Epidemiol. 1991;133:784-94.

85. Klein BE, Moss SE, Klein R, Cruickshanks KJ. Wisconsin epidemiologic study of diabetic R: peak expiratory flow rate: relationship to risk variables and mortality: the Wisconsin epidemiologic study of diabetic retinopathy. Diabetes Care. 2001;24:1967-71.

86. Simons LA, McCallum J, Simons J, Friedlander Y. Relationship of peak expiratory flow rate with mortality and ischaemic heart disease in elderly Australians. Med J Aust. 1997;166:526-9.

87. Arza A, Garzon JM, Hemando A, Aguilo J, Bailon R. Towards an objective measurement of emotional stress: preliminary analysis based on heart rate variability. Conf Proc IEEE Eng Med Biol Soc. 2015;2015:3331-4.

88. Fohr T, Tolvanen A, Myllymaki T, Jarvela-Reijonen E, Rantala S, Korpela R, Peuhkuri K, Kolehmainen M, Puttonen S, Lappalainen R, et al. Subjective stress, objective heart rate variability-based stress, and recovery on workdays among overweight and psychologically distressed individuals: a crosssectional study. J Occup Med Toxicol. 2015;10:39.

89. Jones Kl, Amawi F, Bhalla A, Peacock O, Williams JP, Lund JN. Assessing surgeon stress when operating using heart rate variability and the state trait anxiety inventory: will surgery be the death of us? Color Dis. 2015;17:335-41.

90. Lin SL, Huang CY, Shiu SP, Yeh SH. Effects of yoga on stress, stress adaption, and heart rate variability among mental health professionals-a randomized controlled trial. Worldviews Evid-Based Nurs. 2015:12:236-45.

91. Nilsen C, Andel R, Fritzell J, Kareholt I. Work-related stress in midlife and allcause mortality: can sense of coherence modify this association? Eur J Public Health. 2016;26(6):1055-61.

92. Ginzburg K, Kutz I, Koifman B, Roth A, Kriwisky M, David D, Bleich A. Acute stress disorder symptoms predict all-cause mortality among myocardial infarction patients: a 15-year longitudinal study. Ann Behav Med. 2016;50:177-86.

93. Carlsson AC, Starrin B, Gigante B, Leander K, Hellenius ML, de Faire U. Financial stress in late adulthood and diverse risks of incident cardiovascular disease and all-cause mortality in women and men. BMC Public Health. 2014;14:17.

94. Redmond N, Richman J, Gamboa CM, Albert MA, Sims M, Durant RW, Glasser SP, Safford MM. Perceived stress is associated with incident coronary heart disease and all-cause mortality in low-but not high-income participants in the reasons for geographic and racial differences in stroke study. J Am Heart Assoc. 2013;2:e000447.

95. Paolisso G, Manzella D, Barbieri M, Rizzo MR, Gambardella A, Varricchio M. Baseline heart rate variability in healthy centenarians: differences compared with aged subjects (>75 years old). Clin Sci (Lond). 1999;97:579-84.

96. Tafaro L, Tombolillo MT, Brukner N, Troisi G, Cicconetti P, Motta M, Cardillo E, Bennati E, Marigliano V. Stress in centenarians. Arch Gerontol Geriatr. 2009:48:353-5

97. Franceschi C, Olivieri F, Marchegiani F, Cardelli M, Cavallone L, Capri M, Salvioli S, Valensin S, De Benedictis G, Di lorio A, et al. Genes involved in immune response/inflammation, IGF1/insulin pathway and response to oxidative stress play a major role in the genetics of human longevity: the lesson of centenarians. Mech Ageing Dev. 2005;126:351-61.

98. Marini M, Lapalombella R, Canaider S, Farina A, Monti D, De Vescovi V, Morellini M, Bellizzi D, Dato S, De Benedictis G, et al. Heat shock response by EBV-immortalized B-lymphocytes from centenarians and control subjects: a model to study the relevance of stress response in longevity. Exp Gerontol. 2004;39:83-90.

\section{Submit your next manuscript to BioMed Central and we will help you at every step:}

- We accept pre-submission inquiries

- Our selector tool helps you to find the most relevant journal

- We provide round the clock customer support

- Convenient online submission

- Thorough peer review

- Inclusion in PubMed and all major indexing services

- Maximum visibility for your research

Submit your manuscript at www.biomedcentral.com/submit
Biomed Central 